\title{
Fish intake, mercury, long-chain $n-3$ polyunsaturated fatty acids and risk of stroke in northern Sweden
}

\author{
Maria Wennberg ${ }^{1,2}$, Ingvar A. Bergdahl ${ }^{2}$, Birgitta Stegmayr ${ }^{2}$, Göran Hallmans ${ }^{2}$, Thomas Lundh ${ }^{3}$, \\ Staffan Skerfving ${ }^{3}$, Ulf Strömberg ${ }^{3}$, Bengt Vessby ${ }^{4}$ and Jan-Håkan Jansson ${ }^{1,2}$ \\ ${ }^{1}$ Department of Medicine, Skellefteå Hospital, Skellefteå, Sweden \\ ${ }^{2}$ Department of Public Health and Clinical Medicine, Umeå University, Umeå, Sweden \\ ${ }^{3}$ Department of Occupational and Environmental Medicine, University Hospital, Lund, Sweden \\ ${ }^{4}$ Department of Public Health and Caring Science, Uppsala University, Uppsala, Sweden \\ (Received 16 October 2006 - Revised 8 February 2007 - Accepted 3 April 2007)
}

Results of previous studies on fish intake and stroke risk have been inconclusive. Different stroke types have often not been separated. Our aim was to elucidate whether intake of fish, $\mathrm{Hg}$ or the sum of proportions of fatty acids EPA $(20: 5 n-3)$ and DHA $(22: 6 n-3)$ influence the risk of haemorrhagic or ischaemic stroke. Within a population-based cohort from a community intervention programme, 369 stroke cases and 738 matched controls were identified and included in the present nested case-control study. Information on fish intake had been recorded at recruitment, i.e. before diagnosis. $\mathrm{Hg}$ levels were determined in erythrocyte membranes, also collected at recruitment, and the relative content of fatty acids was measured in erythrocyte membranes or plasma phospholipids. The results showed that in women there was a non-significant decrease in stroke risk with increasing fish intake (OR 0.90 (95\% CI $0.73,1.11)$ per meal per week). The risk in women differed significantly $(P=0.03)$ from that in men, in whom the OR for stroke rose with increasing fish intake (OR 1.24 (95\% CI 1.01, 1.51) per meal per week). The corresponding risk in men for $\mathrm{Hg}$ was 0.99 (95\% CI 0.93, 1.06), and for the sum of proportions of EPA and DHA 1.08 (95\% CI 0.92, 1.28). We conclude that the relationship between stroke risk and fish intake seems to be different in men and women. Increased levels of EPA and DHA do not decrease the risk for stroke and there is no association between stroke risk and $\mathrm{Hg}$ at these low levels.

Fish intake: Stroke: Methyl mercury: Eicosapentaenoic acid: Docosahexaenoic acid

Fish consumption has been reported to have a protective effect against stroke, although studies have not been consistent ${ }^{1,2}$. A possible explanation of the inconsistency could be that fish contains both protective and noxious agents. Examples of such agents are the long-chain fatty acids $20: 5 n-3$ (EPA) and $22: 6 n-3$ (DHA), believed to be beneficial, and $\mathrm{Hg}$, associated with the progression of atherosclerosis in carotid arteries and a potential cause of stroke ${ }^{3}$.

The risk pattern may vary in different types of stroke. Further, there may be differences between men and women ${ }^{4}$.

In the present study, we aim to investigate whether the risk of ischaemic or haemorrhagic stroke is associated with fish intake in men and women, and whether $\mathrm{Hg}$ or EPA plus DHA affects the risk of stroke.

\section{Materials and method}

\section{Study population}

The study population was a community intervention programme on CVD and diabetes (Västerbotten Intervention Programme) and the WHO Multinational Monitoring of
Trends and Determinants in Cardiovascular Disease (MONICA) study in Northern Sweden ${ }^{5,6}$. Participation rates were 59 and $77 \%$, respectively. A study on differences between participants and non-participants indicates that selection bias was small ${ }^{7}$. Up to 20 September 2000, approximately 74000 unique subjects had been screened. Venous blood was sampled; erythrocytes, serum and plasma were separated and stored in a biobank at $-80^{\circ} \mathrm{C}$. Health-screening information was stored in a database.

\section{End points}

From 1 January 1985 to 20 September 2000, a total of 388 first-ever stroke cases fulfilling the inclusion criteria ${ }^{6}$ were identified by the Northern Sweden MONICA incidence registry. The diagnosis of stroke was according to WHO MONICA criteria $^{8}$. The WHO criteria excluded all transient ischaemic attacks, subdural haemorrhages and acute strokes with concomitant brain tumour or severe blood disease. Stroke subtypes were divided into intracerebral haemorrhage, cerebral infarction and unspecified stroke. Haemorrhagic stroke was diagnosed through a positive finding on computerised 
tomography scan and/or autopsy, and in cerebral infarction no sign of haemorrhage on computerised tomography scan or autopsy was allowed. Unspecified stroke had neither computerised tomography scan nor autopsy performed. Cases diagnosed as subarachnoid haemorrhage were excluded since they were few and subarachnoid haemorrhage has another aetiology than intracerebral haemorrhage. Two controls for each case, matched for sex, age ( \pm 2 years), date of health survey ( \pm 1 year) and residential area, were randomly selected from the same health surveys. Subjects were excluded if they had been registered for a previous acute myocardial infarction (AMI) or stroke according to the MONICA registry or for cancer according to the Swedish National Cancer Registry. Controls were excluded if they had died or if they had moved out of the region before the event date of the matched case. We also excluded nineteen triplets, in which the case or both controls were lacking information on fish intake, $\mathrm{Hg}$ and fatty acids, leaving 302 ischaemic, sixty haemorrhagic and seven unspecified stroke cases, and 738 referents. The study was approved by the Research Ethics Committee of Umeå University.

\section{Baseline examination}

Based on the questionnaire of the health screening, smoking habits were classified into daily smoking or non-smoking (including previous and occasional smoking). BMI was calculated as weight $(\mathrm{kg}) /$ height $\left(\mathrm{m}^{2}\right)$. Blood pressure was measured twice at the same occasion and the mean value was recorded. Hypertension was defined as systolic blood pressure $\geq 160 \mathrm{mmHg}$ and/or diastolic blood pressure $\geq 95 \mathrm{mmHg}$, or reported use of anti-hypertensive medication during the previous $14 \mathrm{~d}$. To evaluate the effect of the choice of blood pressure cut-off limit, we also performed analyses with hypertension defined as systolic blood pressure $\geq 140 \mathrm{mmHg}$ and/or diastolic blood pressure $\geq 90 \mathrm{mmHg}$, or reported use of anti-hypertensive medication during the previous $14 \mathrm{~d}$. Diabetes diagnosis was obtained from the questionnaire. Total cholesterol was measured in serum sampled after $>4 \mathrm{~h}$ fasting.

\section{Fish intake}

Average intake over the last year of fatty and lean fish was acquired from a FFQ. The questions asked were: 'How often do you eat lean fish (for example, perch, cod)?'; 'How often do you eat fatty fish (for example, herring, lavaret, salmon)?'; 'How often do you eat salty fish (salt herring)?'. As salt herring is a fatty fish, we assumed that the respondents had included that also in their answer on fatty fish, but for those who reported a more frequent intake of salty fish than of fatty fish (forty-nine subjects out of the total 1048), the estimation of salty fish intake was used as intake of fatty fish. Before statistical analysis the answers were transformed to meals/week of fatty, lean and total fish. The transformations of frequencies to meals/week made were: never $=0$, a few times per year $=0 \cdot 05$, one to three times per month $=0.50$, once per week $=1 \cdot 00$, two to three times per week $=2 \cdot 50$, four to six times per week $=5 \cdot 00$, once per $d=7 \cdot 00$, two to three times per $d=17.5$ and four times per $d$ or more $=28 \cdot 0$. Intake of total fish was also consolidated into five categories; less than once per month, once per month to less than once per week, one to two meals per week, more than twice per week to three meals per week, and more than three meals per week. The latter division in categories is only used in the figures. In Tables and text, OR is calculated per meal per week.

\section{Determination of fatty acid composition}

Fatty acids were determined by GLC after separation of lipids by TLC and transmethylation ${ }^{9}$ and expressed as percentage of all fatty acids analysed (Unit for Clinical Nutrition Research, Department of Public Health and Caring Sciences, Uppsala University, Sweden). The CV of fatty acids measured in plasma phospholipids with this method have previously been measured to $<1-5 \cdot 5 \%$. The fatty acids were identified, by comparing the retention time of each peak with the $\mathrm{Nu}$ Check Prep standards (Nu Check Prep, Elysian, MN, USA) of fatty acid methyl esters. The purity of these standards is greater than $99 \%{ }^{11}$.

Fatty acids were determined by measuring plasma phospholipids in the first 113 cases and their controls. In contrast, in the subsequent 256 cases and controls we used erythrocyte membranes.

\section{Mercury determination}

Determination of total $\mathrm{Hg}$ was made in duplicate in aciddigested erythrocytes by cold vapour atomic fluorescence spectrometry ${ }^{12}$ (Department of Occupational and Environmental Medicine, Lund University Hospital, Sweden). The limit of detection was $0.15 \mu \mathrm{g} / \mathrm{l}$. The method imprecision, calculated as the CV for duplicate measurements, was $4.0 \%$. The analytical accuracy was checked using Seronorm (Nycomed Pharma, Oslo, Norway: 2.2 (SD 0.20) and 13 (SD 0.58) $\mu \mathrm{g} / \mathrm{l} v$. recommended 3.0 and $14 \mu \mathrm{g} / \mathrm{l}$, respectively) and at Centre de Toxicologie du Quebec, Canada (1.9 (SD 0.09) and 9.2 (SD $0 \cdot 30) \mu \mathrm{g} / \mathrm{l} v$. certified $2 \cdot 0$ and $9.4 \mu \mathrm{g} / \mathrm{l}$, respectively).

\section{Statistics}

The effect of each potential risk factor was first examined by univariate conditional logistic regression based on the matched case-control sets ${ }^{13,14}$. In the initial univariate analyses, the potential risk factors were not transformed or categorised (if not originally categorical). We then selected candidate risk factors for the multivariate analyses based on the results from the univariate analyses; each potential risk factor with a $P$ value from the Wald or likelihood-ratio tests $^{14}$ less than 0.25 was selected ${ }^{13}$. A candidate risk factor may act as an independent risk factor, confounder or effect modifier in a multivariate setting. In order to proceed to the multivariate modelling, we analysed Spearman's correlations ${ }^{15}$ between the candidate risk factors. Finally, to obtain the most importantly influential factors among the candidate risk factors, we built the multivariate models using conditional logistic regression techniques ${ }^{13}$. Besides the effects on all-stroke risk, we analysed the effects on haemorrhagic and ischaemic stroke, respectively, by restricting the analyses to the relevant matched case-control sets. A $P$ value $\leq 0.05$ was considered statistically significant. 
The statistical computations were carried out using SPSS for Windows (version 11.5; SPSS Inc., Chicago, IL, USA) and EGRET for Windows (version 2.0; CYTEL Software Corporation, Cambridge, MA, USA).

\section{Results}

For the whole population, median levels of $\mathrm{Hg}$ and $\mathrm{EPA}+\mathrm{DHA}$ were $3.63 \mathrm{ng} \mathrm{Hg} / \mathrm{g}$ erythrocytes and $5.75 \%$, respectively, while mean fish intake was 1.43 meals/week. Among cases, diabetes, hypertension and daily smoking were significantly more common. Cases had higher serum cholesterol and BMI than controls (Table 1).
In the first part of the series of consecutive cases and their referents, we analysed EPA + DHA in plasma phospholipids, while in the latter part in erythrocyte membranes. The levels in these two series did not differ substantially. Nevertheless, we evaluated the effect of modification of series; no such effect was present $(P=0 \cdot 96)$.

Fish intake was positively correlated with erythrocyte $\mathrm{Hg}$ content $(P<0.001 ;$ Fig. 1$)$ and EPA + DHA $(P<0.001$; Fig. 2). There was a strong correlation between $\mathrm{Hg}$ and $\mathrm{EPA}+$ DHA (Table 2).

In the univariate analyses, fish intake, but not erythrocyte $\mathrm{Hg}$ content or EPA + DHA, were associated with stroke risk (Table 3).

Table 1. Baseline characteristics for controls, all stroke patients and patients with ischaemic and haemorrhagic stroke (Mean values and standard deviations)

\begin{tabular}{|c|c|c|c|c|c|c|c|c|c|}
\hline & \multirow[b]{3}{*}{$n$} & & & \multicolumn{6}{|c|}{ Strokes } \\
\hline & & \multicolumn{2}{|c|}{ Controls (n 738) } & \multicolumn{2}{|c|}{ All (n 369) } & \multicolumn{2}{|c|}{$\begin{array}{l}\text { Ischaemic } \\
\text { (n 302) }\end{array}$} & \multicolumn{2}{|c|}{$\begin{array}{l}\text { Haemorrhagic } \\
(n 60)\end{array}$} \\
\hline & & Mean & SD & Mean & SD & Mean & SD & Mean & SD \\
\hline \multicolumn{10}{|l|}{ Age (years) } \\
\hline Men & 666 & $54 \cdot 6$ & $8 \cdot 2$ & $54 \cdot 6$ & $8 \cdot 2$ & $54 \cdot 9$ & $8 \cdot 0$ & $54 \cdot 1$ & $8 \cdot 6$ \\
\hline Women & 441 & $55 \cdot 4$ & $8 \cdot 0$ & $55 \cdot 4$ & $8 \cdot 1$ & $55 \cdot 0$ & $8 \cdot 2$ & $57 \cdot 4$ & $6 \cdot 8$ \\
\hline \multicolumn{10}{|c|}{ Smokers (\%) } \\
\hline Men & 649 & \multicolumn{2}{|c|}{$20 \cdot 0$} & \multicolumn{2}{|c|}{$25 \cdot 6$} & \multicolumn{2}{|c|}{$24 \cdot 3$} & \multicolumn{2}{|c|}{$26 \cdot 8$} \\
\hline Women & 419 & \multicolumn{2}{|c|}{$17 \cdot 2$} & \multicolumn{2}{|c|}{$26 \cdot 4^{\star}$} & \multicolumn{2}{|c|}{$26 \cdot 0$} & \multicolumn{2}{|c|}{33.3} \\
\hline \multicolumn{10}{|c|}{ Self-reported diabetes (\%) } \\
\hline Men & 650 & \multicolumn{2}{|c|}{$2 \cdot 06$} & \multicolumn{2}{|c|}{$7 \cdot 48^{*}$} & \multicolumn{2}{|c|}{$8 \cdot 28$} & \multicolumn{2}{|c|}{$4 \cdot 76$} \\
\hline Women & 422 & \multicolumn{2}{|c|}{1.06} & & & & & & \\
\hline Academic & cation & & & & & & & & \\
\hline Men & 632 & & & & & & & & \\
\hline Women & 411 & & & & & & & & \\
\hline Hypertensi & & & & & & & & & \\
\hline Men & 654 & & & & & & & & \\
\hline Women & 431 & & & & & & & & \\
\hline Diastolic B & $\mathrm{nmHg}$ ) & & & & & & & & \\
\hline Men & 651 & 86 & 10 & $91^{*}$ & 11 & 89 & 11 & 95 & 10 \\
\hline Women & 429 & 84 & 9 & $88^{*}$ & 9 & 87 & 9 & 91 & 10 \\
\hline Systolic BP & $\mathrm{mHg})$ & & & & & & & & \\
\hline Men & 651 & 136 & 18 & $144^{*}$ & 19 & 142 & 19 & 153 & 17 \\
\hline Women & 429 & 137 & 19 & $145^{\star}$ & 23 & 144 & 23 & 148 & 20 \\
\hline Serum cho & erol (m & & & & & & & & \\
\hline Men & 651 & 6.07 & $1 \cdot 19$ & $6 \cdot 34^{*}$ & $1 \cdot 37$ & $6 \cdot 41$ & 1.39 & $6 \cdot 05$ & $1 \cdot 19$ \\
\hline Women & 433 & $6 \cdot 37$ & $1 \cdot 30$ & 6.53 & $1 \cdot 34$ & 6.51 & 1.35 & $6 \cdot 33$ & 1.07 \\
\hline BMI $\left(\mathrm{kg} / \mathrm{m}^{2}\right.$ & & & & & & & & & \\
\hline Men & 646 & $26 \cdot 1$ & $3 \cdot 2$ & $26 \cdot 9^{\star}$ & 3.6 & $26 \cdot 6$ & 3.3 & $28 \cdot 0$ & $4 \cdot 2$ \\
\hline Women & 434 & $26 \cdot 0$ & $4 \cdot 3$ & $27 \cdot 3^{*}$ & $5 \cdot 2$ & $27 \cdot 2$ & $5 \cdot 1$ & $27 \cdot 2$ & $5 \cdot 4$ \\
\hline Fish intake & eals/we & & & & & & & & \\
\hline Men & 616 & $1 \cdot 30$ & $1 \cdot 29$ & 1.47 & $1 \cdot 27$ & 1.42 & $1 \cdot 20$ & 1.59 & 1.45 \\
\hline Women & 415 & 1.56 & 1.45 & 1.55 & 1.42 & 1.52 & 1.37 & $1 \cdot 32$ & 0.73 \\
\hline Erythrocyte & $(n g / g)$ & & & & & & & & \\
\hline Men & 599 & 3.72 & $3 \cdot 71$ & 3.68 & 3.03 & $3 \cdot 86$ & 3.09 & 3.68 & $2 \cdot 88$ \\
\hline Women & 394 & 3.55 & $3 \cdot 80$ & 3.43 & $3 \cdot 22$ & 3.39 & 3.01 & $4 \cdot 24$ & 4.59 \\
\hline EPA (\%)† & & & & & & & & & \\
\hline Men & 638 & $1 \cdot 29$ & 0.48 & $1 \cdot 30$ & 0.55 & $1 \cdot 31$ & 0.52 & $1 \cdot 26$ & 0.68 \\
\hline Women & 430 & $1 \cdot 29$ & 0.53 & $1 \cdot 30$ & 0.51 & $1 \cdot 32$ & 0.51 & $1 \cdot 15$ & 0.50 \\
\hline $\mathrm{DHA}(\%) \dagger$ & & & & & & & & & \\
\hline Men & 634 & 4.35 & 1.00 & 4.44 & 0.98 & $4 \cdot 47$ & 1.01 & $4 \cdot 32$ & 0.82 \\
\hline Women & 429 & 4.62 & 1.06 & 4.57 & 1.08 & 4.62 & 1.08 & $4 \cdot 14$ & $1 \cdot 15$ \\
\hline $\mathrm{EPA}+\mathrm{DH}$ & \%)† & & & & & & & & \\
\hline Men & 634 & $5 \cdot 61$ & $1 \cdot 33$ & $5 \cdot 78$ & $1 \cdot 36$ & 5.85 & $1 \cdot 38$ & $5 \cdot 65$ & $1 \cdot 31$ \\
\hline Women & 429 & $5 \cdot 88$ & 1.43 & $5 \cdot 81$ & 1.45 & 5.91 & 1.45 & $5 \cdot 15$ & 1.52 \\
\hline
\end{tabular}

$\mathrm{BP}$, blood pressure; EPA + DHA, sum of proportions of EPA and DHA.

* Percentage or mean value was significantly different from that of the control group $(P \leq 0.05)$.

† Values are medians. 


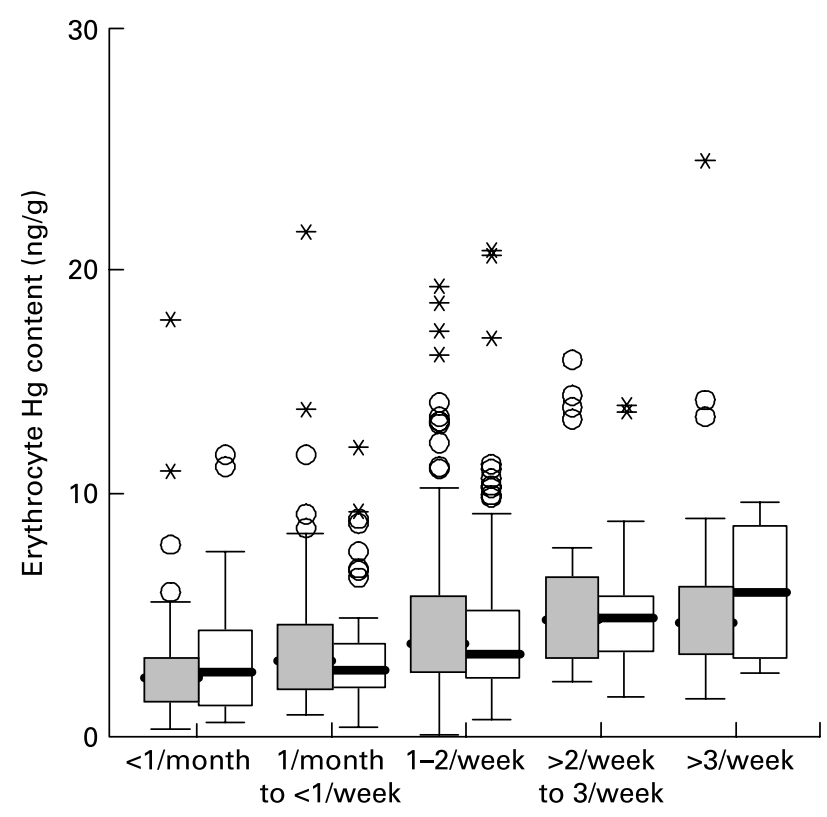

Fish intake (meals)

Fig. 1. Hg levels in erythrocyte membranes in categories with different fish intake $\left(R_{\mathrm{S}} 0.29(P \leq 0.001)\right.$ for men; $R_{\mathrm{s}} 0.30(P \leq 0.001)$ for women). Each box shows the median and quartiles for men ( $\square$ ) and women ( $\square$ ). Outliers $(\mathrm{O})$ and extremes $\left({ }^{*}\right)$ are shown. Erythrocyte $\mathrm{Hg}$ values over $30 \mathrm{ng} / \mathrm{g}$ erythrocytes $(n 3)$ are excluded.

For multivariate analysis, serum cholesterol level, smoking, BMI, diabetes and blood pressure were selected as candidate risk factors, besides fish intake. Serum cholesterol level did not contribute significantly to the multivariate model,

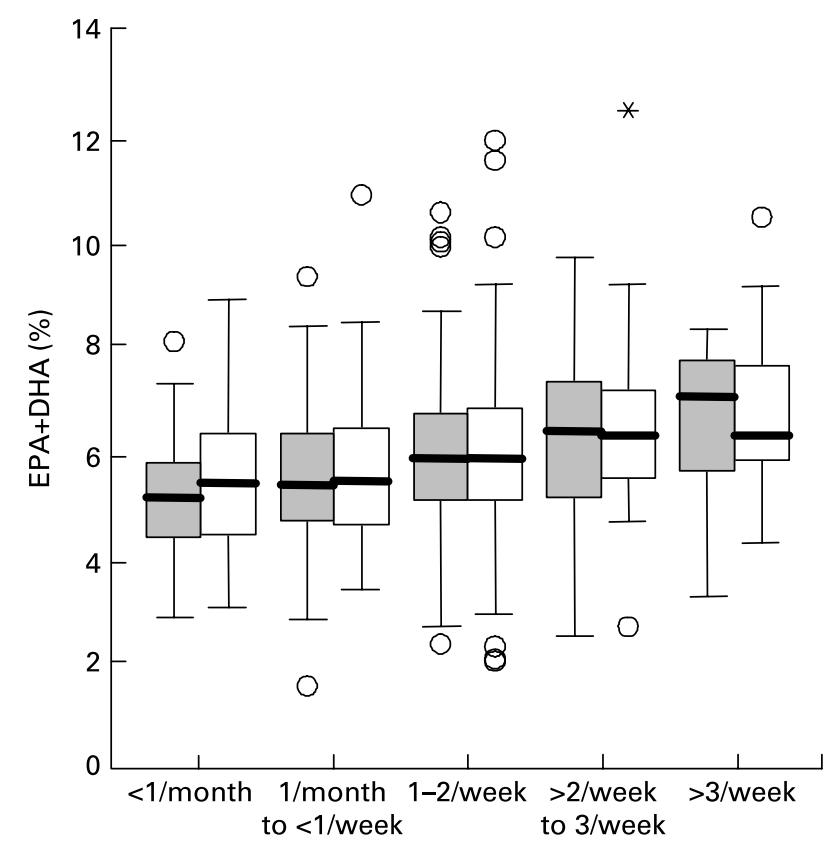

Fish intake (meals)

Fig. 2. Sum of proportions of EPA and DHA in plasma phospholipids (113 cases; 226 controls) and in erythrocyte membranes (256 cases; 512 controls $)$ in categories with different fish intake $\left(R_{\mathrm{S}} 0.26(P \leq 0.001)\right.$ for men; $R_{\mathrm{S}} 0.22(P \leq 0.001)$ for women). Each box shows the median and quartiles for men $(\square)$ and women $(\square)$. Outliers $(O)$ and extremes $\left({ }^{*}\right)$ are shown. and did not noticeably affect the effect estimates of the other candidate risk determinants. Therefore serum cholesterol was not included in the final multivariate model.

The effect of fish intake was significantly modified by sex $(P=0.03)$. There was an association between increased risk for all types of stroke and high fish intake in males (Table 4, Fig. 3) and the association with stroke was only marginally different for reported intake of fatty fish, compared with lean fish (Table 4). Reported lean and fatty fish intakes were clearly correlated (Table 2). In females high fish intake was non-significantly associated with decreased risk for stroke (Table 4, Fig. 3). The OR shown in Fig. 3 are in accordance with the model assumption of a multiplicative risk used in Tables 2 and 3. The estimated effect of fish intake on stroke risk did not differ greatly when restricting the multivariate analysis to ischaemic ( $83 \%$ of the cases) or haemorrhagic stroke (Table 4).

In order to investigate the influence of the biomarkers $\mathrm{EPA}+\mathrm{DHA}$ and $\mathrm{Hg}$ on risk, we replaced fish intake in the multivariate model with these, one at a time. Then, for men, there was no statistically significant increase of the risk for all strokes, neither for EPA + DHA (OR 1.08 (95\% CI $0.92,1.28)$ ), nor for $\mathrm{Hg}$ (OR 0.99 (95\% CI 0.93, 1.06)). For ischaemic stroke in men, there was an almost statistically significant increase of the risk for EPA + DHA (OR 1.20 (95\% CI $0.99,1.46)$ ), but not for $\mathrm{Hg}(\mathrm{OR} 1.00$ (95\% CI 0.93, 1.07)). For women, there was no association between all-stroke risk and EPA + DHA (OR 0.98 (95\% CI 0.81, 1.17)) or Hg (OR $1.00(95 \%$ CI $0.94,1.08))$. A similar lack of statistically significant associations was obtained for ischaemic stroke in women (data not shown).

Since the variable hypertension also includes use of antihypertensive medication, this variable, instead of systolic or diastolic blood pressure, was selected for the multivariate analysis. When hypertension was replaced by systolic or diastolic blood pressure, only minor changes occurred. With systolic blood pressure instead of hypertension, the OR for fish intake changed from 1.24 (95\% CI 1.01, 1.51) to $1.26(95 \%$ CI 1.03, 1.54) for men. Exchange to diastolic blood pressure changed the OR to 1.27 (95\% CI 1.04, 1.55) for men. No changes were detected for women. Statistical analysis with systolic blood pressure $\geq 140 \mathrm{mmHg}$ and/or diastolic blood pressure $\geq 90 \mathrm{mmHg}$, or reported use of anti-hypertensive medication during the last $14 \mathrm{~d}$, as cut-offs for hypertension, gave results similar to those with the cut-off limits of 160/ 95; for men, the OR for fish intake changed from 1.23 to $1 \cdot 28$, still significant, and for women the OR for fish intake changed from 0.90 to 0.93 , still non-significant. Effects of other risk factors also changed only marginally; the greatest change was found for hypertension, where the OR increased from 2.13 (95\% CI $1.54,2.95)$ to 2.74 (95\% CI $1.94,3 \cdot 86)$.

\section{Discussion}

Fish intake was associated with an increased risk for stroke, but only in men. Neither $\mathrm{Hg}$, nor EPA + DHA, was associated with the risk of total stroke, although a non-significant tendency was observed for ischaemic stroke and $\mathrm{EPA}+\mathrm{DHA}$ in men. Since there were few haemorrhagic stroke cases in each group, when men and women were separated, no conclusive results can be drawn on risk of 
Table 2. Spearman rank correlations (bivariate analyses) between risk factors for stroke and factors associated with fish intake in 369 cases and 738 controls†

\begin{tabular}{|c|c|c|c|c|c|}
\hline & Fish & Lean fish & Fatty fish & Erythrocyte $\mathrm{Hg}$ & $\mathrm{EPA}+\mathrm{DHA}$ \\
\hline \multicolumn{6}{|l|}{ Men } \\
\hline Lean fish & $0 \cdot 78^{\star \star \star}$ & - & & & \\
\hline Fatty fish & $0.71^{\star \star \star}$ & $0.22^{\star \star \star}$ & - & & \\
\hline Erythrocyte $\mathrm{Hg}$ & $0.31^{\star * *}$ & $0.20^{\star \star \star}$ & $0.30^{\star \star *}$ & - & \\
\hline $\mathrm{EPA}+\mathrm{DHA}$ & $0.28^{\star \star \star}$ & $0 \cdot 14^{\star * \star}$ & $0.27^{\star \star \star}$ & $0.44^{\star * *}$ & - \\
\hline Serum cholesterol & 0.020 & 0.002 & 0.030 & 0.056 & -0.013 \\
\hline Smoking & -0.055 & -0.043 & -0.034 & -0.038 & -0.060 \\
\hline BMI & -0.001 & -0.039 & 0.047 & $0.095^{\star}$ & $0.12^{\star *}$ \\
\hline Diabetes & 0.041 & $0.098^{*}$ & -0.059 & 0.031 & -0.021 \\
\hline Hypertension & 0.025 & -0.004 & 0.038 & 0.018 & $0.12^{\star \star}$ \\
\hline SBP & 0.014 & -0.064 & 0.071 & 0.037 & 0.041 \\
\hline DBP & 0.048 & 0.000 & $0.082^{*}$ & 0.015 & 0.069 \\
\hline Age & 0.005 & -0.031 & 0.053 & $0.12^{\star *}$ & $0 \cdot 17^{\star \star *}$ \\
\hline \multicolumn{6}{|l|}{ Women } \\
\hline Lean fish & $0.77^{\star \star \star}$ & - & & & \\
\hline Fatty fish & $0 \cdot 74^{\star \star *}$ & $0 \cdot 26^{\star * *}$ & - & & \\
\hline Erythrocyte $\mathrm{Hg}$ & $0.33^{\star \star \star}$ & $0 \cdot 16^{\star \star}$ & $0.30^{\star \star \star}$ & - & \\
\hline $\mathrm{EPA}+\mathrm{DHA}$ & $0 \cdot 24^{\star \star *}$ & $0 \cdot 16^{\star *}$ & $0 \cdot 24^{\star \star *}$ & $0.50^{\star \star *}$ & - \\
\hline Serum cholesterol & 0.063 & 0.030 & $0 \cdot 12^{\star}$ & $0 \cdot 15^{\star *}$ & 0.068 \\
\hline Smoking & -0.095 & -0.067 & -0.089 & $-0 \cdot 10^{\star}$ & $-0.13^{\star *}$ \\
\hline BMI & $0.18^{\star \star *}$ & $0 \cdot 18^{\star \star \star}$ & $0.13^{\star}$ & 0.031 & 0.030 \\
\hline Diabetes & 0.049 & 0.046 & 0.026 & -0.017 & -0.038 \\
\hline Hypertension & 0.047 & -0.040 & $0 \cdot 10^{*}$ & -0.027 & 0.052 \\
\hline SBP & $0 \cdot 12^{*}$ & 0.051 & $0.15^{\star \star}$ & -0.005 & 0.058 \\
\hline DBP & $0 \cdot 12^{*}$ & 0.023 & $0 \cdot 15^{\star *}$ & -0.029 & 0.001 \\
\hline Age & 0.028 & $-0.11^{\star}$ & $0 \cdot 18^{\star \star \star}$ & 0.086 & 0.079 \\
\hline
\end{tabular}

haemorrhagic stroke. However, for fish intake and risk of haemorrhagic stroke, the trend was similar to that of ischaemic stroke.

Despite nominal statistical significance of the relationship of fish intake with stroke in men, and of a different relationship of fish intake with stroke in women than in men, we cannot completely rule out that the present findings are due to chance. First, we made several comparisons and have made no adjustment for multiple comparisons. Second, relatively few participants were found outside the one to two meals/week category, so we have limited power to estimate risk at high and low fish intake. Nevertheless, the data

Table 3. Univariate conditional logistic regression analyses concerning the influence of potential risk factors on all-stroke risk, based on 369 matched sets of one case and two controls

\begin{tabular}{|c|c|c|c|c|c|}
\hline Risk factor & Unit or category & Missing cases $(n)$ & Missing controls $(n)$ & $\mathrm{OR}^{*}$ & $P \dagger$ \\
\hline \multicolumn{6}{|l|}{ Fish-related risk factors } \\
\hline Fish intake & Meals/week & 30 & 46 & 1.13 & 0.05 \\
\hline Lean fish intake & Meals/week & 24 & 36 & 1.12 & 0.19 \\
\hline Fatty fish intake & Meals/week & 22 & 37 & $1 \cdot 17$ & 0.07 \\
\hline $\mathrm{Hg}$ in erythrocytes & $\mathrm{ng} / \mathrm{g}$ & 34 & 80 & 1.00 & 0.84 \\
\hline $\mathrm{EPA}+\mathrm{DHA}$ & $\%$ & 9 & 35 & 1.02 & 0.66 \\
\hline \multicolumn{6}{|l|}{ Background risk factors } \\
\hline Serum cholesterol & $\mathrm{mmol} / \mathrm{l}$ & 8 & 15 & $1 \cdot 16$ & 0.004 \\
\hline Smoking & No & 14 & 25 & $1 \cdot 0$ & 0.008 \\
\hline & Yes & & & 1.54 & \\
\hline BMI & $\mathrm{Kg} / \mathrm{m}^{2}$ & 8 & 19 & 1.06 & $<0.001$ \\
\hline Self-reported diabetes & $\begin{array}{l}\text { No } \\
\text { Yes }\end{array}$ & 14 & 21 & $\begin{array}{l}1.0 \\
3.70\end{array}$ & $<0.001$ \\
\hline Academic education & $\begin{array}{l}\text { No } \\
\text { Yes }\end{array}$ & 21 & 43 & $\begin{array}{l}1.0 \\
0.89\end{array}$ & 0.56 \\
\hline Hypertension & $\begin{array}{l}\text { No } \\
\text { Yes }\end{array}$ & 9 & 13 & $\begin{array}{l}1 \cdot 0 \\
2 \cdot 17\end{array}$ & $<0.001$ \\
\hline Diastolic BP & $\mathrm{mmHg}$ & 12 & 15 & 1.05 & $<0.001$ \\
\hline Systolic BP & $\mathrm{mmHg}$ & 12 & 15 & 1.03 & $<0.001$ \\
\hline
\end{tabular}

EPA + DHA, sum of proportions of EPA and DHA; BP, blood pressure.

* OR, reflecting multiplicative increase in risk per unit increase for non-categorical risk factors, or in relation to the reference category (with OR 1.0) for categorical risk factors.

†From the Wald test, reflecting the degree of influence of the potential risk factor. 
Table 4. Multivariate conditional logistic regression analyses concerning the effects of the candidate risk factors on all-stroke risk, ischaemic stroke risk and haemorrhagic stroke risk†

\begin{tabular}{|c|c|c|c|c|c|c|}
\hline Risk factor & Unit & Cases $(n)$ & Controls $(n)$ & OR $\ddagger$ & $95 \% \mathrm{Cl}$ & $P$ \\
\hline \multicolumn{7}{|l|}{ All-stroke risk } \\
\hline Total fish intake* & Meals/week & & & & & \\
\hline Males & & 189 & 342 & 1.24 & $1.01,1.51$ & 0.04 \\
\hline Females & & 128 & 228 & 0.90 & $0.73,1.12$ & 0.35 \\
\hline Fatty fish intake & Meals/week & & & & & \\
\hline Males & & 195 & 356 & 1.29 & $0.95,1.83$ & 0.06 \\
\hline Females & & 129 & 231 & 0.82 & $0.58,1.15$ & 0.24 \\
\hline Lean fish intake & Meals/week & & & & & \\
\hline Males & & 194 & 352 & 1.23 & $0.94,1.62$ & $0 \cdot 14$ \\
\hline Females & & 128 & 232 & 0.98 & $0.74,1.30$ & 0.91 \\
\hline \multicolumn{7}{|c|}{ Ischaemic stroke risk } \\
\hline Total fish intake & Meals/week & & & & & \\
\hline Males & & 147 & 271 & 1.25 & $1.00,1.56$ & 0.04 \\
\hline Females & & 111 & 197 & 0.93 & $0.74,1.17$ & 0.51 \\
\hline Fatty fish intake & Meals/week & & & & & \\
\hline Males & & 152 & 282 & 1.25 & $0.93,1.65$ & 0.14 \\
\hline Females & & 112 & 200 & 0.91 & $0.64,1.28$ & 0.58 \\
\hline Lean fish intake & Meals/week & & & & & \\
\hline Males & & 152 & 281 & 1.33 & $0.97,1.82$ & 0.07 \\
\hline Females & & 112 & 201 & 0.96 & $0 \cdot 70,1 \cdot 30$ & 0.77 \\
\hline \multicolumn{7}{|c|}{ Haemorrhagic stroke risk } \\
\hline Total fish intake & Meals/week & & & & & \\
\hline Males & & 39 & 65 & 1.14 & $0.69,1.88$ & 0.59 \\
\hline Females & & 15 & 27 & 0.61 & $0.23,1.57$ & 0.31 \\
\hline Fatty fish intake & Meals/week & & & & & \\
\hline Males & & 40 & 68 & 1.42 & $0.71,2.85$ & 0.32 \\
\hline Females & & 15 & 27 & 0.28 & $0.07,1.10$ & 0.07 \\
\hline Lean fish intake & Meals/week & & & & & \\
\hline Males & & 39 & 65 & 0.86 & $0.38,1.93$ & 0.71 \\
\hline Females & & 15 & 27 & $1 \cdot 11$ & $0.54,2.29$ & 0.77 \\
\hline
\end{tabular}

* The effect of fish intake was significantly modified by sex $(P=0.03)$.

$\dagger$ Diabetes, hypertension, BMI and smoking are included in the model, in addition to fish intake.

$\ddagger O R$, reflecting multiplicative increase in risk per unit increase for the (non-categorical) risk determinants of fish intake.

showed increased stroke risk in men in the more than two meals/week categories.

The results were not anticipated. A difference between men and women is not surprising (see later), but we had expected an association with $\mathrm{Hg}$ and/or $\mathrm{EPA}+\mathrm{DHA}$, since these agents have been implicated in prior studies. EPA + DHA was associated with a trend of an increased risk for ischaemic stroke in men; this was opposite to the expected, but may be explained by the fact that EPA and DHA are known biomarkers for fish intake ${ }^{16}$. There was a fairly close association between fish intake and concentrations of $\mathrm{Hg}$ and $\mathrm{EPA}+\mathrm{DHA}$, indicating that the estimation of fish intake from questionnaires is valid. Therefore, the question arises if the present results are only an effect of random variation or if they indicate that another causative agent than $\mathrm{Hg}$ is present in fish.

The lack of associations between stroke risk and $\mathrm{Hg}$ is not due to analytical errors; the analytical methods for $\mathrm{Hg}$ and EPA + DHA showed good precision. We only analysed total $\mathrm{Hg}$ concentrations. Since the dominating $\mathrm{Hg}$ species in erythrocyte membranes in this region of Sweden is methyl $\mathrm{Hg}$, we assume that it is acceptable to analyse total $\mathrm{Hg}^{17}$. The exposure level of $\mathrm{Hg}$ was low in this population, which may explain the lack of association with stroke risk. We chose to include the sum of proportions of EPA and DHA, since separate analysis did not contribute further.
A strength of the present study design is that the blood samples were obtained before the event. However, they only reflect a relatively short time period, often years before the onset of the stroke, and the levels change fairly rapidly after an alteration in intake of methyl $\mathrm{Hg}^{18}$ and EPA + DHA. However, this is not a problem, since it is well known that fish intake habits prevail for long time periods ${ }^{19}$.

In statistical modelling, we analysed possible confounders. Adjustment for matching factors was inherent in the design. We also included other factors (smoking, BMI, cholesterol, diabetes, hypertension) associated with stroke, thus representing potential confounders. We used hypertension rather than diastolic and systolic blood pressure, since the latter are affected by medication. Only minor changes were detected when hypertension was replaced by diastolic or systolic blood pressure.

In the present study, increased levels of $\mathrm{Hg}$ and $\mathrm{EPA}+\mathrm{DHA}$ were not associated with a decreased risk of stroke. This differs from the picture seen in the same region of Sweden for AMI, in which both $\mathrm{Hg}$ and EPA + DHA were predictors of a decreased risk ${ }^{16}$, most likely because they are indicators of fish intake, a possible preventive factor for $\mathrm{AMI}^{20,21}$. In the present study fish intake seemed to be associated with increased risk of ischaemic stroke in men, but the effect appears to be small compared with the protective effect on AMI. 


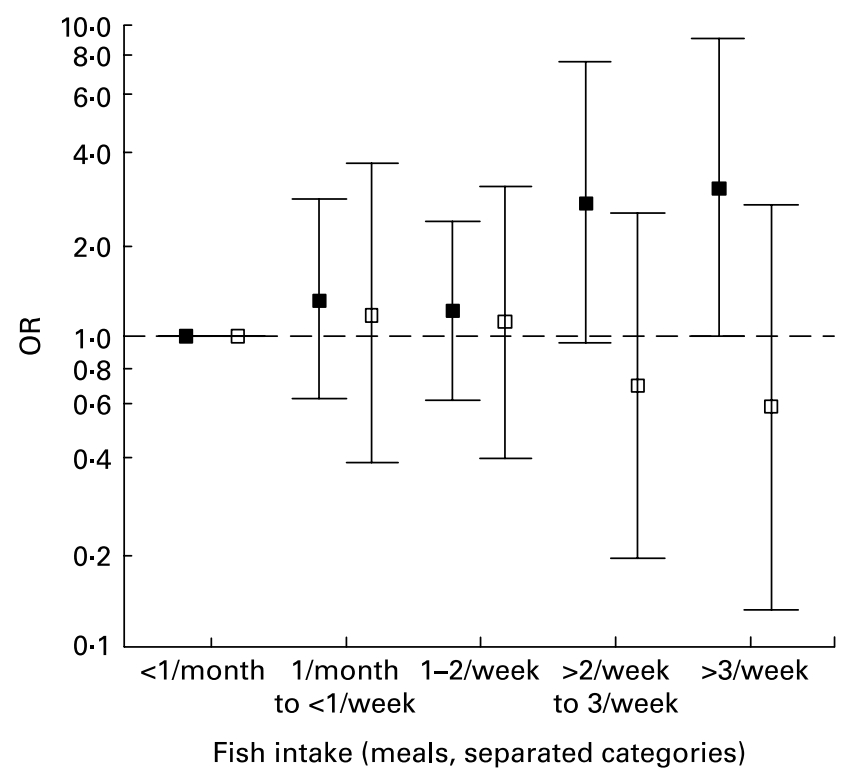

Fig. 3. Effects of fish intake on all-stroke risk in men ( $\square$ ) and women ( $\square$ ), by five categories of fish intake in a multivariate model including also smoking, diabetes, hypertension and BMI. The numbers of cases and controls in each category that contributed to the multivariate model were: $15+45(<1$ meal/month), $39+72$ ( $\geq 1 \mathrm{meal} / \mathrm{month}$ to $<1 \mathrm{meal} /$ week $), 106+234(1-2$ meals/week), $17+25$ ( $>2$ to $\leq 3$ meals/week) and $12+15$ ( $>3$ meals/ week) for males; $7+19,22+45,81+147,10+28$ and $8+19$ for females. Values are OR, with $95 \% \mathrm{Cl}$ represented by vertical bars, for different categories of fish intake, which is different from Tables 3 and 4 where OR is calculated per meal per week.

The present lack of a protective effect of EPA + DHA on stroke is in accordance with some other investigations ${ }^{22,23}$ and with the general concept that stroke is associated with other risk factors than AMI.

The present data indicate that fish intake is a risk determinant. This is contrary to the meta-analyses by $\mathrm{He}$ et al. ${ }^{1}$ and Bouzan et $a l^{2}$, but in accordance with some previous data $^{23,24}$. The increased stroke risk appears at relatively high fish intake (more than two meals/week) and only in men. A sex difference similar to the one that appeared in the present study has been observed in previous studies of stroke ${ }^{4}$ and $\mathrm{IHD}^{25}$. Therefore, explanations of the conflicting results from different studies may lie in (a) the unknown shape of the dose-response curve, which may have a threshold or be U- or J-shaped, and (b) different effects in men and women. It is also possible that the associations of fish consumption with other lifestyle habits, which may appear as predictors of stroke, differ between populations.

Further clarification of the epidemiology of stroke and fish intake is hampered by the fact that the mechanism behind the effect of fish is not known. In the present study, it is most probably not due to $\mathrm{Hg}$. Thus, other contaminants in fish should be considered. One of the most prevalent in fish in Sweden, and other areas, is persistent organic halogenated pollutants ${ }^{26,27}$, but we know of no evidence that those cause vascular disease. Fish intake gives exposure to amines ${ }^{28}$, which may react with nitrite in the stomach to form nitrosamines, known mutagens, which hypothetically may induce atherosclerosis.

\section{Conclusion}

The effect of fish intake on stroke risk seems to be different in men and women. There was no decrease in stroke risk with increased levels of EPA + DHA, and no association between stroke risk and $\mathrm{Hg}$ could be demonstrated at these low levels. Even if fish intake may be a risk determinant for ischaemic stroke in men, this does not mean that we recommend a reduction of fish consumption. If there is a factor in fish increasing stroke risk in men, it should be identified, and if possible - eliminated.

\section{Acknowledgements}

The study was supported by grants from the Medical Faculties, Universities of Umeå and Lund, the Swedish Research Council/Medicine, Swedish Research Council for Environment, Agricultural Sciences and Spatial Planning, National Swedish Environment Protection Agency, Swedish Council for Working Life and Social Research, the County Council of Southern Sweden and the European Union (Sixth Framework Programme; PHIME; FOOD-CT-2006-016253). The paper reflects only the authors' views; the European Union is not liable for any use that may be made of the information.

\section{References}

1. He K, Song Y, Daviglus ML, Liu K, Van Horn L, Dyer AR, Goldbourt U \& Greenland P (2004) Fish consumption and incidence of stroke: a meta-analysis of cohort studies. Stroke 35, 1538-1542.

2. Bouzan C, Cohen JT, Connor WE, Kris-Etherton PM, Gray GM, Konig A, Lawrence RS, Savitz DA \& Teutsch SM (2005) A quantitative analysis of fish consumption and stroke risk. Am J Prev Med 29, 347-352.

3. Salonen JT, Seppanen K, Lakka TA, Salonen R \& Kaplan GA (2000) Mercury accumulation and accelerated progression of carotid atherosclerosis: a population-based prospective 4-year followup study in men in eastern Finland. Atherosclerosis 148, 265-273.

4. Gillum RF, Mussolino ME \& Madans JH (1996) The relationship between fish consumption and stroke incidence. The NHANES 1 epidemiologic follow-up study (National Health and Nutrition Examination Survey). Arch Intern Med 156, 537-542.

5. Weinehall L, Johnson O, Jansson JH, Boman K, Huhtasaari F, Hallmans G, Dahlen GH \& Wall S (1998) Perceived health modifies the effect of biomedical risk factors in the prediction of acute myocardial infarction. An incident case-control study from northern Sweden. J Intern Med 243, 99-107.

6. Stegmayr B, Lundberg V \& Asplund K (2003) The events registration and survey procedures in the Northern Sweden MONICA Project. Scand J Public Health 61, Suppl., 9-17.

7. Weinehall L, Hallgren CG, Westman G, Janlert U \& Wall S (1998) Reduction of selection bias in primary prevention of cardiovascular disease through involvement of primary health care. Scand J Prim Health Care 16, 171-176.

8. Tunstall-Pedoe H (1988) WHO MONICA Project Principal Investigators. The World Health Organization MONICA Project (Monitoring Trends and Determinants in Cardiovascular Disease); a major international collaboration. J Clin Epidemiol 41, 105-114.

9. Boberg M, Croon LB, Gustafsson IB \& Vessby B (1985) Platelet fatty acid composition in relation to fatty acid composition in plasma and to serum lipoprotein lipids in healthy subjects with special reference to the linoleic pathway. Clin Sci (Lond) 68 581-587. 
10. Smedman A, Gustafsson IB, Berglund LG \& Vessby BO (1999) Pentadecanoic acid in serum as a marker for intake of milk fat: relations between intake of milk fat and metabolic risk factors. Am J Clin Nutr 69, 22-29.

11. Wirfalt E, Vessby B, Mattisson I, Gullberg B, Olsson H \& Berglund G (2004) No relations between breast cancer risk and fatty acids of erythrocyte membranes in postmenopausal women of the Malmo Diet Cancer cohort (Sweden). Eur J Clin Nutr 58, 761-770.

12. Sandborgh-Englund G, Elinder CG, Langworth S, Schutz A \& Ekstrand J (1998) Mercury in biological fluids after amalgam removal. J Dent Res 77, 615-624.

13. Hosmer D \& Lemeshow S (1989) Applied Logistic Regression. New York: Wiley.

14. Clayton D \& Hills M (1993) Statistical Models in Epidemiology. Oxford: Oxford University.

15. Altman D (1991) Practical Statistics for Medical Research. London: Chapman \& Hall.

16. Hallgren CG, Hallmans G, Jansson JH, Marklund SL, Huhtasaari F, Schutz A, Stromberg U, Vessby B \& Skerfving S (2001) Markers of high fish intake are associated with decreased risk of a first myocardial infarction. Br J Nutr 86, 397-404.

17. Wennberg M, Lundh T, Bergdahl IA, Hallmans G, Jansson JH, Stegmayr B, Custodio HM \& Skerfving S (2006) Time trends in burdens of cadmium, lead and mercury in the population of northern Sweden. Environ Res 100, 330-338.

18. World Health Organization (1990) International Programme on Chemical Safety Environmental Health Criteria no. 101: Methylmercury. Geneva: WHO.

19. Rylander L, Stromberg U \& Hagmar L (1998) Agreement between reported fish consumption obtained by two interviews and its impact on the results in a reproduction study. Eur J Epidemiol 14, 93-97.

20. He K, Song Y, Daviglus ML, Liu K, Van Horn L, Dyer AR \& Greenland P (2004) Accumulated evidence on fish consumption and coronary heart disease mortality: a meta-analysis of cohort studies. Circulation 109, 2705-2711.

21. Konig A, Bouzan C, Cohen JT, Connor WE, Kris-Etherton PM, Gray GM, Lawrence RS, Savitz DA \& Teutsch SM (2005) A quantitative analysis of fish consumption and coronary heart disease mortality. Am J Prev Med 29, 335-346.

22. Morris MC, Manson JE, Rosner B, Buring JE, Willet WC \& Hennekens CH (1995) Fish consumption and cardiovascular disease in the physicians' health study: a prospective study. Am J Epidemiol 142, 166-175.

23. Caicoya M (2002) Fish consumption and stroke: a community case-control study in Asturias, Spain. Neuroepidemiology 21, 107-114.

24. Orencia AJ, Daviglus ML, Dyer AR, Shekelle RB \& Stamler J (1996) Fish consumption and stroke in men. 30-year findings of the Chicago Western Electric Study. Stroke 27, 204-209.

25. Jarvinen R, Knekt P, Rissanen H \& Reunanen A (2006) Intake of fish and long-chain $n-3$ fatty acids and the risk of coronary heart mortality in men and women. Br J Nutr 95, 824-829.

26. Svensson BG, Nilsson A, Hansson M, Rappe C, Akesson B \& Skerfving S (1991) Exposure to dioxins and dibenzofurans through the consumption of fish. $N$ Engl J Med 324, 8-12.

27. Asplund L, Svensson BG, Nilsson A, Eriksson U, Jansson B, Jensen S, Wideqvist U \& Skerfving S (1994) Polychlorinated biphenyls, 1,1,1-trichloro-2,2-bis(p-chlorophenyl)ethane ( $\mathrm{p}, \mathrm{p}^{\prime}$-ddt) and 1,1dichloro-2,2-bis(p-chlorophenyl)-ethylene (p, $\mathrm{p}^{\prime}$-dde) in human plasma related to fish consumption. Arch Environ Health 49, 477-486.

28. Svensson BG, Nilsson A, Jonsson E, Schutz A, Akesson B \& Hagmar L (1995) Fish consumption and exposure to persistent organochlorine compounds, mercury, selenium and methylamines among Swedish fishermen. Scand J Work Environ Health 21, 96-105. 